\title{
RASGOS DISCURSIVOS \\ DE LA NARRATIVA MINERA BOLIVIANA
}

\author{
POR \\ LUIS H. ANTEZANA \\ Universidad Catolica, Cochabamba
}

\begin{abstract}
«Hay que conocer un campamento minero en Bolivia para descubrir cuánto puede resistir el hombre» (ALMARAZ: Los cementerios mineros).
\end{abstract}

\begin{abstract}
«Agapito Tarquino había muerto hacía mucho y dizque por idéntica razón allá en la mina no hay minero que no le rinda culto prendiendo religiosamente todos los viernes una vela a su alma aunque por otra parte es bien sabido que Agapito Tarquino no ha muerto ni mucho menos sino que vive en tenebrosos parajes cerca del Tío para velar eternamente por sus hermanos los mineros» (SÁENZ: No es así nomás).
\end{abstract}

La explotación minera es, desde la colonia, una de las marcas más notables y conocidas del territorio boliviano. Potosí, Huanchaca, La Salvadora, las Tesis de Pulacayo, Siglo XX, la FSTMB, la Nacionalización de las Minas son -recurriendo a este leve y torpe cuerpo de símbolosíndices de complejos procesos sociales que, de una $\mathbf{u}$ otra manera, han determinado - y algunos todavía determinan - la vida histórica de este país. Convergentemente, el discurso literario conforma un entorno textual que acompaña, casi paso a paso, a las diversas formas y contenidos de esta dimensión productiva. Siguiendo el hilo conductor de la Narrativa minera boliviana (1983), antologada por René Poppe, veremos de diseñar los rasgos más salientes de este discurso narrativo tan íntimamente vinculado al complejo sociohistórico afín a la producción minera en Bolivia.

En general, ésta es una narrativa fundamentalmente realista, aunque frecuenta dimensiones míticas y fantásticas, sobre todo cuando toca las cosmovisiones afines al «interior mina». Referencialmente, sus inscripciones suponen los diversos avatares - históricos y estructurales- de la ex- 
plotación minera en este territorio. Visto de lejos, hay una cierta continuidad referencial que le sirve de tela-de-fondo: suceden los hechos, sucede la narrativa. Los mejores textos evitan el mecanismo implícito en este proceder; otros, simplemente desplazan el discurso literario hacia la crónica o el periodismo. Con todo, prima una lógica de intensidad más que de saturación. Es decir, las nominaciones tienden a destacar y tratar momentos y situaciones «ejemplares» más que a detallar —ideal, por otra parte, imposible - todo lo que ocurriría en las minas bolivianas. A la larga, surgen ciertos paradigmas -Potosí, en el pasado; Siglo XX y su entorno, actualmente- donde las inscripciones literarias van y vuelven frecuentemente conformando un cierto espesor semántico que, finalmente, construye una especie de modelo dominante, «ejemplar». Ahí, el campamento o distrito mineros son -digamos abstrayendo un poco- como nudos donde convergen múltiples hilos y tensiones. Desde ya, el «exterior» e «interior mina», dos de los campos más explícitos de esta narrativa, se definirían bajo ese modelo general, fruto de las reiteraciones. Por este lado se pueden armar (des-armar) algunas características de este tipo de literatura. Limitándonos a lo discursivo, veamos, pues, algunos de sus rasgos.

El párrafo anterior destaca, un poco, la tradicional «prioridad de lo real» que caracterizaría, en grueso, a esta narrativa. Sin embargo, las cosas no son tan simples. A manera de contraste, quizá extremo, pero muy ilustrativo, examinemos brevemente un texto-Aluvión de fuego (1937), de Oscar Cerruto-, el cual parece sugerir que, como diría Nelson Goodman, es la realidad la que, en rigor, imita a la literatura. En la tercera parte de la novela, en las páginas dedicadas a la mina de Espíritu Santo, hay una manifestación de trabajadores mineros. Al frente de la multitud, obedeciendo más a un impulso que a una convicción, va Jacinta, toda vestida de rojo, «como una alegre bandera». La manifestación se transforma en masacre y, finalmente, Jacinta yace «como un coágulo de sangre» junto a las otras víctimas. $\mathrm{Si}$, siguiendo las referencias, reconstituimos el contexto, ésta no es más que una clara versión de la triste y difundida «Masacre de María Barzola» ${ }^{1}$. Pero Cerruto publica Aluvión de fuego en 1937 y la «Ma-

${ }^{1}$ Esta masacre recibe su nombre de María Barzola, tuna mujer —quiere la tradición- que encabezaba la muchedumbre agitando una bandera boliviana. En Llallagua (1977), Roberto Querejazu Calvo le dedica un capítulo a estos sucesos («La masacre de Catavi», 1984, pp. 237-257) y concluye así sobre su importancia relativa: «Los 13 muertos y 39 heridos iban a tener significación histórica. Hubo otros muertos y heridos en las minas en épocas anteriores, pero las circunstancias políticas no fueron las mismas» (p. 269). La «masacre de María Barzola» marca el principio del fin del patiñismo y cae dentro de la amplia movilización popular que llevará al '52 y, por ahí, a la nacionalización de las minas. Junto a otros textos más breves, dos novelas, Mina (1953) de Alfredo Guillén Pinto y Natty Peñaranda 
sacre de María Barzola» sucede en 1942. El paralelismo total es tan notable, que la primera reacción es suponer, como adelantamos, que la realidad imita a la literatura. Sin embargo, la hipótesis más plausible es que la obra de Cerruto permitió una verbalización que, con el correr del tiempo, explicita los hechos de 1942. Es decir, la discursividad literaria, en este caso, es un modelo - un medio - por el cual los hechos pasan hacia una discursividad más amplia: la historia, digamos, y por ahí, a la «memoria popular». De todas maneras, la prioridad acrítica de lo real frente a lo literario queda en entredicho. Es que lo factual y lo verbal no operan en estancos autónomos - pese a la tradición metafísica al respecto- y se las arreglan para intercambiar sus términos y pertinencias ${ }^{2}$.

Un permanente espacio de encuentro entre lo verbal y lo factual es la enunciación (allí donde «alguien dice algo»). En esta narrativa hay un gesto muy frecuente que tiende a vincular, por medio de la enunciación precisamente, lo literario con el punto-de-vista de los actores sociales. Sobre todo hay una flecha de valoración (identificación, complicidad) donde el «narrador» - digamos en gruesa categoría- se diseña solidario con el trabajador minero. Ya Luis Capoche, en 1585, señalaba lo inhumano del trabajo en las minas coloniales (en Poppe 1983, pp. 3-6). En muchos textos, un índice de estos pasajes discursivos es el del narrador, que de partida se presenta ajeno a la vida minera. Esta extrañeza demarca de dos maneras: una de hecho, otra de origen. En el primer caso, la situación de enunciación es no minera - tipo «observador circunstancial»-, pero integra dentro de su relato la narración testimonial de un actor minero ${ }^{3}$. En el segundo caso, el narrador destaca su origen urbano, como un «colegial», «estudiante» o «desocupado» que va a trabajar a las minas, y allí asume

de Guillén, y El precio del estaño (1960, versión corregida 1980), hacen de esta masacre el tema central de sus preocupaciones.

${ }^{2}$ Asumiendo una pertinencia propia para cada ámbito (lo factual, aquí; lo verbal, allí), ¿dónde se daría el entrecruce? Una teoría de los discursos nos indica un posible terreno: allí donde los hechos se verbalizan en función histórica. Un campo afín al de las ideologías y las ciencias humanas, como fácilmente se puede reconocer. La narrativa se desplazaría hacia/en verbalizaciones semejantes. En esta vena, la «literalidad» de la literatura, valga la expresión, sería, sobre todo, una manera de ordenar lo verbal; lo que no impide una ordenación en función de «lo real».

${ }^{3}$ En «Scherzo de una gota de agua», de Luis E. Heredia (en Poppe 1983, pp. 6269), por ejemplo, el narrador — que anda evocando, por contraste, su vida en Parísrecoge un relato, el de «don Segundino», que es el que da contenido minero al relato. Otro tipo de integración indirecta es aquel que practica Oscar Soria en «Sangre en San Juan» (en Poppe 1983, pp. 104-112). Ahí, obviando tun narrador representado, Soria recoge testimonios mineros diversos y los integra reproduciéndolos tal cual fueron grabados (y se inscriben las «fuentes»). En ambos casos, entre muchos, la narrativa se desplaza hacia el «idioma original» del trabajador minero. 
el punto-de-vista de un minero ${ }^{4}$. En ambos casos hay pasajes discursivos que privilegian la experiencia en las minas como último criterio, se diría, de verdad. Por ahí lo factual y lo verbal van articulando sus términos. Aquí, como en el positivismo lógico, la verdad de los enunciados elementales depende de la experiencia. La complicidad del narrador con el actor social es, también, un tránsito verbal: se recoge un «idioma elemental» extraño en un caso, se lo aprende en el otro.

Un texto ejemplar al respecto es Canchamina (1956), de Víctor Hugo Villegas y Mario Guzmán Aspiazu. Esta novela corta es, dicho sea de paso, una de las mejores obras del género - aunque el símbolo de su desenlace, luego de la Nacionalización de las Minas el 1952, no alcance a cristalizar. Bajo el recurso del «manuscrito encontrado» (cf. el Quijote), Villegas y Guzmán desplazan en varios grados la enunciación no minera para privilegiar el «idioma elemental» —sigamos utilizando la imagende la experiencia minera. De partida, el primer narrador (un «nosotros») no haría otra cosa que transcribir un manuscrito que le(s) entrega un ex trabajador minero. Es un breve «Diario». En este texto, el segundo narrador nunca deja de señalar su origen ajeno a la mina, y sin ocultar su solidaridad por los trabajadores, marca una infranqueable distancia entre él, que es sólo un pulpero, y los «verdaderos» mineros. La marca más notable de este encadenamiento de distanciamientos solidarios es la explícita inscripción de un nivel de (auto)reflexión en torno a la propia novela minera:

Yo no quiero ser un mixtificador a la usanza de los tantos que escriben sobre la «mina adentro», sin siquiera haber ganado unos cuantos jornales al tope de las galerías. La novela de la mina - repito, de la mina adentro- tiene que ser obra de un hijo de la mina (p. 96).

Consecuentes con este criterio, los autores privilegian el «exterior mina». Nuevamente, pues, hay ese «idioma elemental» de la experiencia minera que se inscribe como último criterio de verdad. Y hacia allí, buscando quizá «verdad» para sus enunciados, tienden las flechas de la narrativa minera boliviana.

“ En «La leyenda del 'Tío' en el socavón "Caracoles'», de Vicente Terán Erquicia (en Poppe 1983, pp. 46-56), el narrador es un «colegial» que ahora trabaja en «interior mina». Un extraño encuentro que tiene será explicado, por un viejo minero, como un encuentro con el "Tío»: «Desde entonces seguía al igual que los demás mineros, saludando a todos los que me cruzaban el camino, especialmente en los callejones abandonados» (p. 56). En «Desde el barro dolorido», de José Barrón Feraudi (en Poppe 1983, pp. 150-158), el narrador es un «estudiante» empleado de «carrero». Allí le explicarán lo de la «Callapera», núcleo de su relato. Este cuento, dicho sea de paso, es «raro», pues pone en escena una mujer que trabaja en «interior mina". 
Desde un punto de vista discursivo, este gesto, frecuente y dominante, no es inocente. La valoración implícita en él supone textos previos. En primer lugar y en general, la narración asume un texto capaz de valorar distintivamente el papel de los trabajadores mineros... y su «idioma». En textos recientes, no es difícil reconocer discursos teóricos, políticos e ideológicos que motivan un tan discernimiento -el discurso de las «clases sociales», por ejemplo-. En un mínimo - el de la mera solidaridad humana- cuánto de previo hay: posiciones éticas, reglas sociales y, frecuentemente por estos lados, el cristianismo. En esta vena, al «tomar partido», la narración literaria lee, pues, otro discurso, el que verbalizó el papel de los actores sociales en las minas. Ahí se inscribe la flecha de valoración solidaria. Pero, por otra parte, no habría que desdeñar la posibilidad de que, bajo ciertos aspectos, es el propio discurso literario el que establecería un tan discernimiento. Al respecto, el discurso literario boliviano, en general, ha ejercido una especie de suplencia cognoscitiva, en la medida en que las ciencias sociales no estaban, por así decirlo, bien constituidas por estos lares. A su manera, la literatura hizo algo de sociología, de antropología, de historia. En lo que vamos viendo, dominaría una práctica more anthropologica, donde se privilegia el conocimiento del propio actor social. Bajo estas condiciones, el gesto enunciativo señalado indica también lugares que la narrativa minera ocupa en un campo discursivo más amplio y múltiple: ora opera sobre distinciones conceptuales previas, ora las produce. Siempre es literatura, pero sus funciones discursivas están sujetas a diversos espesores.

En estos pasajes y relaciones, el gesto de identificación enunciativa implica también un espesor connotativo no siempre explícito, pero que es uno de los a priori de esta narrativa: originariamente, el trabajador minero es campesino (es decir, indigena). De ahí que, como vimos, la marca de un origen urbano («colegial», «estudiante», «desocupado») suponga siempre una distancia infranqueable, aunque se viva y trabaje en las minas. E1 trabajador minero «sustantivo» es de origen campesino. Sin duda, el arquetipo de esta suposición es el mitayo, o sea, el indígena obligado a trabajar en las minas como parte del sistema colonial. Este a priori motiva toda aquella vida de «exterior mina» que tiene que ver con lo campesino o indígena. Un buen indicador de los desplazamientos ahí implicados es, a nivel de lenguaje narrativo, el de los múltiples préstamos idiomáticos, del quechua y del aymara, que siembran esta narrativa ${ }^{5}$.

${ }^{5}$ Un texto muy forzado al respecto, pero ilustrativo por ello mismo, es «Cuelga asustado», de Guillermo Delgado (en Poppe 1983, pp. 192-197). En Canchamina (cf., supra) - evidenciando el mecanismo, se diría-, cada capítulo se acompaña de un glosario donde se explicitan los términos quechuas y aymaras. También se en- 
El «exterior mina» es un espacio horizontal de relaciones. Supone, digamos desde una poética, un entramado metonímico. Un polo notable de desplazamientos e implicaciones mutuas es, pues, el que vincula la mina con el campo. «Detrás» hay una compleja muñeca rusa que siempre tiene un nuevo factor en juego. Como si la narrativa minera se escribiera sobre la narrativa indigenista. Ilustrativamente, aunque ciertamente los hechos - reales y literarios- son más matizados, podemos sugerir — como imagen - un minicírculo vicioso que, con variables históricas, explicita brevemente los vínculos campo-mina. Bajo un mercado fuertemente determinado «desde arriba», el campo provee a la mina productos a bajo precio, de modo que el salario del minero le alcance para sobrevivir; dados los precios mínimos, los campesinos se ven obligados a buscar otro tipo de vida más rentable... y van a trabajar a las minas. Por cosas así, salvo algunas extrapolaciones pueblerinas, la vida en el distrito o campamento mineros se figura, muy a menudo, en términos campesinos. Desde ya, casi cualquier texto un poco extenso tomado al azar podría ejemplificar esa constante descriptiva. Es parte del a priori mencionado. En todo ello hay un rasgo común que apunta, diría, a toda una cosmovisión: la precariedad.

Si el campo previo a la migración hacia la mina se presenta como un lugar inhóspito debido a sus carencias -o a la invasión territorial frecuente en épocas previas a la reforma agraria de 1953-, la vida en la mina se diseña como una especie de «situación límite» donde la muerte prematura rige soberanamente. Los hombres no van a las minas, son arrojados a ellas. Esta narrativa carece, en general, de humor, pero suele inscribir la ironía que supone irse a las minas: El Dorado es sólo un espejismo ${ }^{6}$. Los desplazamientos campo-mina, entonces, obedecen a un nomadismo sin término fijo y signado por la precariedad.

En este medio -el «exterior mina»- se podría señalar también la figura de la mujer en esta narrativa. Desde ya, la esposa del trabajador minero y la palliri, mujer que trabaja el mineral en la superficie, se diseñan con claros rasgos indígenas. La precariedad de este mundo parece signarlas aún más gravemente que a los hombres. Son como las sombras de un destino trágico. En estos casos, la narración es cómplice, solidaria...

cuentran explicitados algunos términos «técnicos» propios al trabajo minero en Bolivia.

${ }^{6}$ Esta amarga ironía atraviesa, en rigor, toda la narrativa minera. Desde ya, ahí están todas aquellas «ilusiones perdidas» de los campesinos que buscan en la mina una mejor vida y encuentran muy poco o nada. La reiterada presencia del accidente o la enfermedad también intensifican ese sinsentido. A la larga, una de las «leyes secundarias» de la narrativa minera es, si se puede decir, la que destaca la inutilidad de las pasiones humanas en tal contexto. 
y piadosa. En general, la mujer es raramente un «personaje» en esta narrativa; es, sobre todo, una serie de «figuras», de «tipos» femeninos. El texto más matizado en su presentación es, otra vez, Canchamina. Ahí se las ve en su cotidianeidad: recogiendo mínimos alimentos en la pulpería, soportando los niños, los nacimientos y las muertes. E1 anonimato con que las caracterizan Villegas y Guzmán — «la mujer de Sirpa», «la mujer de Luna», "la mujer de Andaluce»...- indica apropiadamente el lugar marginal que, en general, ocupan. Pero, por otra parte, hay otra serie de figuras femeninas que se marcan más esquiva e inquietantemente. Una de esas figuras es la viuda. La viudez en las minas no es nada simple. Muerto el marido, la mujer debe dejar la mina. A menudo, para sobrevivir, la mujer toma otro compañero. «Hay mujeres -escribe Sergio Almaraz en Los cementerios mineros - que han sido tres veces viudas. A la mujer de un camarada muerto se la busca y se le pide que cuide de uno» (en Poppe 1983, p. 330). Estas mujeres tienen algo de la misma mina: ellas siguen mientras los hombres cambian y pasan. Extremando la figura, en «La devoradora», marcando a su personaje con una fría racionalidad, Raúl Botelho Gosálvez hace de la «viuda de las minas» un cuasi símbolo de un cruel y desquiciado mundo.

Se trata de una "viuda de las minas». ¿Sabes qué es eso? No me interrumpas y luego saca tus conclusiones. Timotea Mamani pertenece a un género de mujeres aún no catalogadas en la delincuencia. Como la araña "viuda negra», que después de ayuntarse y ser fecundada se devora al macho como banquete nupcial, así ella ha procedido tres veces... En la soledad de los campamentos mineros, siempre es posible hallar una víctima. He ahí, querido Jorge, lo que hizo Timotea Mamani... iSe casó con un enfermo y lo exterminó a caricias para heredar su seguro social! (en Poppe 1983, p. 79).

Estas inquietantes figuras quizá connotan la tradición minera, que ve un mal presagio en la presencia de una mujer en el «interior mina». Y, más allá, en múltiples imágenes, la mina misma se figura como una mujer terrible análoga a la «araña negra» mencionada por Botelho. Así, por ejemplo, la presenta Luis Alfonso Fernández en Las amapolas también tienen sangre: «La mina, con sus fauces de sombra estrujada, exhibía en sus aristas una evocación de mantones cancerosos y senos embalsamados», como dice en su rebuscada prosa, con claras connotaciones femeninas (en Poppe 1983, p. 93). Finalmente, la mujer en la mina también se inscribe en figuras afines a una vida pueblerina - del pueblo, por ejemplo, tal como se lo presenta, con carácter de arquetipo, en La Chaskañawi (1947)-. Son las mujeres que viven en torno a la chichería, el alcohol y la fiesta, los paliativos 
circunstanciales de la vida del minero. Son figuras ambiguas. A veces las marca el lucro en los negocios; otras, alguna situación extrema que las arrojó a las minas. Ahí la narración no es directamente negativa, pero deja un aura inquietante afín, seguramente, a la precariedad existencial típica de los distritos y campamentos mineros de esta narrativa. Algunas de ellas, como la Jacinta de Aluvión de fuego, pasan de la fiesta a la muerte sin mayores transiciones.

Si un hilo tenso y frecuente tiene que ver con lo indígena y campesino, en la misma horizontalidad, el «exterior mina» supone relaciones con la más amplia vida social y política bolivianas. Cuantitativamente, éste es el tema más frecuentado por la narrativa minera. Esta articulación tiene, ciertamente, un fondo histórico; basta pensar, por ejemplo, en el papel que la plata y el estaño tuvieron en la configuración de esta sociedad. La mina se diseña como un territorio tenso donde se concentran - demostrativamente- los conflictos sociales bolivianos en su forma más intensa y extrema. El paradigma conflictivo que opone a trabajadores mineros y patrones - y el Estado sería también patronal a partir de la Nacionalización de las Minas- es otro de los a priori de esta narrativa ${ }^{7}$. Las minas son escenarios donde se representan —en el sentido «ejemplar» del términolos problemas sociales bolivianos. En este marco, la narrativa frecuenta una terrible constante: la invasión estatal del distrito minero; invasión que, a menudo, se traduce en masacre. Este extremo - nada «literario», en última instancia, como la película $E l$ coraje del pueblo, de Jorge Sanjinés, documenta claramente- pone al desnudo los límites de la vida estatal boliviana. El proceso en su conjunto toma, a la larga, la forma de una ecuación indiferente a los matices gubernamentales: las injusticias en el trabajo minero provocan pedidos que se traducen en huelgas y manifestaciones, y éstas son acalladas por una invasión militar del distrito. La muerte colectiva signa el fin del proceso. El distrito minero se marca, finalmente, como un territorio ocupado y, por tanto, ajeno, inhóspito e inhumano. En su

${ }^{7}$ Se ha visto (M. J. MacLeod, 1971) una suerte de cansador maniqueísmo en esta persistente inscripción. Sin embargo, más allá de una simplificación, en la medida que la vida en las minas - y, por ahí, la narrativa minera boliviana- concentran las tensiones sociales de este territorio, el enfrentamiento entre mineros y militares es, en toda verosimilitud, una de las constantes de la historia boliviana en lo que va del siglo. Al respecto, en su ensayo «Las masas en noviembre» (1983), René Zavaleta Mercado destaca: «La historia de Bolivia, al menos a partir de los cuarenta, es eso, un duelo entre el ejército y la clase obrera (habrá que repetirlo siempre). Es sólo un modo de decir las cosas: un duelo entre el bloque que ha debido resignarse a su intríngulis represiva pura y un bloque alternativo que está bajo la dirección práctica de la clase obrera aunque dentro de los límites de una hegemonía incompleta» (p. 42, subrayado del autor). 
más extensa connotación, esta ocupación toca las fronteras de un símbolo: el que entiende a la sociedad civil boliviana como un espacio invadido —dominado- por... otros.

En este marco podríamos destacar, brevemente, el cuento «La masacre», de Walter Montenegro (en Poppe 1983, pp. 81-92). Todos los elementos del proceso señalado están ahí: las necesidades y la organización obrera, la invasión, la manifestación y la masacre. Estas, algunas imágenes:

Se acurrucó entre los cuerpos de la mujer de Gutiérrez y de Chungara, obligando al niño, a viva fuerza, a tenderse también. Los silbidos de las balas tejían una jaula de muerte sobre los cuerpos inmóviles.

Vio la gigantesca figura de Peñaloza avanzando por entre el polvo. Su brazo giró en el aire, y dos segundos más tarde se oyó una violenta explosión en el campo de los soldados. La fusilería y las ametralladoras enmudecieron por un instante, luego reanudaron su fuego aún más rabiosamente.

Un coro de aullidos extrahumano llenaba el ambiente. Una voz de mujer parecía rasgar el aire con un cuchillo. Navarro se revolvió y alcanzó a ver a una palliri que hacía esfuerzos por levantarse, apoyándose en una mano. Con la otra, trataba de contener una masa blanco-rojiza de intestinos y sangre que salía por entre los jirones de la pollera (p. 91).

Montenegro intensifica esta situación cruelmente arquetípica introduciendo un enmascarado juego de oposiciones intersubjetivas. Para el maestro Navarro, Chungara, el recién llegado, es un "vendido», un traidor. Sus. actitudes parecen confirmar la sospecha. Pero Chungara morirá en la masacre protegiendo con su cuerpo el de un niño. Navarro sólo tiene un gesto para enmendar - tarde - su error: él mismo se encargará de enterrar a Chungara, el vendido.

Dado el gesto de identificación enunciativa ya señalado, la reinscripción constante de la masacre minera tiende a conformar un amplio texto de denuncia, testimonio, crítica, reclamo y condena sociales. Esto es relativamente efectivo y ha habido un caso donde esa denuncia literaria tuvo un efecto social notable (cf. infra). Pero, al mismo tiempo, hay una cierta ambiguiedad discursiva en esta reiterada serie de inscripciones. En cierta forma, ahí se insiste en diseñar un límite insuperable, algo así como la inscripción de una ley objetiva y, como tal, irremediable. Uno se pregunta si, en alguna medida, este hecho «cultural» -manejando categorías antropológicas - no se vincula connotativamente con el fatalismo propio a ciertos hechos "naturales», como sequías y pestes, que suelen motivar comprensiones análogas en otras tradiciones. Aunque el gesto narrativo es, 
digamos, pro minero, la fuerte presencia de la masacre en esta literatura también parece una inscripción indirecta, pese a las buenas intenciones, de la «ley» del sistema...

En una visión más general, la inscripción de la masacre minera es parte de todo un «sistema» connotativo que esta narrativa trata de conformar. No es que todos los elementos en juego entren en un armado coherente, pero el desplazamiento de las inscripciones y su acumulación bajo una perspectiva dominante - el gesto enunciativo- connotan un vínculo «sistemático». Por así decirlo, las condiciones de vida, el accidente, el derrumbe, las enfermedades, los abusos, la masacre, en fin, la «precariedad» de la que hablábamos antes, son otras tantas manifestaciones de un despiadado destino. Tendencialmente, pues, el texto amplio de la narrativa minera boliviana connota un «texto trágico». Entrar a trabajar en la mina implica asumir una muerte prematura por accidente, maltrato, enfermedad, masacre, etc. En este conjunto, donde los elementos intercambian sus sentidos, donde lo natural y lo cultural tienden a mezclarse, la masacre tiene un rasgo propio: es una muerte prematura, pero de carácter social, colectivo. El destino, ahí, hunde sus razones en una problemática, ciertamente, social. Y por ahí se iría articulando - aunque los bordes y la coherencia son siempre vagos - ese «sistema» connotativo que metonímicamente tiende a subordinar las diversas inscripciones bajo una problemática que, a la larga, pone en escena las dimensiones represivas de la sociedad boliviana. Si la narrativa minera permaneciera en este «sistema» de inscripciones - bajo los ojos del "exterior mina», digamos- sería una cerrada, fuertemente marcada por la muerte prematura. Pero, por otro lado, la muerte adquiere otros sentidos en la narrativa de «interior mina»; sentidos que, aunque no lo niegan, desplazan el «texto trágico» hacia otros orbes donde la clausura no es tan definitiva. Veremos, pero antes, un desarrollo complementario.

El efecto de denuncia - crítica, testimonio- implícito en la narrativa minera depende de las condiciones históricas de recepción. De partida, la literatura, en general, tiene nulo o poco eco en la sociedad boliviana. Es solamente un discurso fuertemente restringido. Pero en lo que nos ocupa, un texto de clara denuncia, El metal del diablo (1946), de Augusto Céspedes, desempeñó un papel no despreciable en la desfiguración social del patiñismo. El contexto de su recepción fue el de la amplia crítica social, que, después de la guerra del Chaco (1932-1935), iba socavando el «superestado minero» de Patiño, Hoschild y Aramayo; crítica que culminaría en la insurrección popular de 1952, uno de cuyos efectos fue la Nacionalización de las Minas. En este caso, el discurso narrativo se inscribe dentro de una más amplia discursividad política e ideológica, la que sirve de medio 
para ampliar los alcances del texto literario ${ }^{8}$. Pero con el correr del tiempo, en otras condiciones de recepción, el texto «retorna» a la mera literatura. Con el patiñismo como cosa del pasado, El metal del diablo depende menos del contexto, y ahí Zenón Omonte vive más a su manera y menos como caricatura crítica del «magnate del estaño». En general, las condiciones históricas de la recepción determinan los posibles efectos sociales de un $x$ texto literario, en este caso de la narrativa minera.

Si la narrativa de "exterior mina» supone desplazamientos horizontales, la de «interior mina» es, literal y conceptualmente, vertical, y ahí, se diría, priman procesos de condensación metafórica. No bien la «jaula» deja la superficie, el descenso hacia los socavones es, nomás, la entrada a un mundo oscuro, laberíntico, inscrito casi siempre bajo fuertes connotaciones dantescas. El «interior mina» es el nivel cero de la narrativa minera, como programaban los autores de Canchamina (cf. supra); en él se condensan e intensifican los diversos factores y tensiones que la caracterizan. Discursivamente, un rasgo notable de esta narrativa de «interior mina» es que en ella el tradicional y dominante discurso realista no sólo da lugar, aquí y allá, a un discurso fantástico, sino que a la larga se le subordina. A nivel objetivo, se puede argüir que esa dimensión fantástica es real, es decir, propia a los trabajadores mineros y sus tradiciones. Ciertamente, pero en tal caso lo real conjuga algo más que un mero discurso realista. Parte de la labor de estas páginas es, precisamente, destacar la multiplicidad discursiva que caracterizaría lo real de esta narrativa. El «idioma elemental» del que hablábamos (cf. supra) tiene un activo componente fantástico.

El discurso fantástico de la narrativa de «interior mina» asume dos funciones: una explicativa y otra referencial. En su función explicativa, el discurso fantástico es un metalenguaje que, como sistema cognoscitivo, motiva, comprende, articula este universo de seres y hechos. En su función referencial, este discurso puebla el «interior mina» - y a veces el «exterior»- con seres y hechos que, por contraste, escapan al cotidiano y realista. En su límite, ambas funciones se superponen. (La razón de esta condensación sería la siguiente: el nivel explicativo supone a menudo «seres» que operan en lo referencial.) Pero, con todo, las funciones son discernibles.

Proponiendo un hilván more historico, se diría que, en un principio, una cierta presencia de lo excepcional en la vida minera se traduce en

${ }^{3}$ En general, los discursos político e ideológico parecen ser los medios más aptos para la amplificación social de otros discursos; el literario, entre ellos. Pero, de todas maneras, las condiciones históricas de la recepción condicionan el alcance de los posibles efectos sociales. El eco necesita una cámara de resonancia. 
explicaciones sobrenaturales propias a la tradición cristiana. Al respecto, un relato de Bartolomé Arzáns y Vela, referido a 1677, atribuye a un milagro del Santo Cristo la salvación de un minero perdido en los socavones, y además explica su buena fortuna (en Poppe 1983, pp. 7-11). Luego hay una introducción todavía indirecta de las concepciones propias al «interior mina»; no se las asume de inmediato, sino que se las recoge como «creencias», «leyendas», mitos», parte de las tradiciones indígenas. Narrativamente, estas inscripciones toman la forma de «cuento dentro del cuento» ${ }^{9}$. Finalmente, como en la narrativa de René Poppe ${ }^{10}$, se inscribe directamente un entrecruce entre lo realista y lo fantástico, donde en última instancia lo segundo incluye lo primero. Estas tres esquemáticas posibles etapas sugieren una lógica discursiva múltiple: 1) lo fantástico, como sobrenatural, interviene milagrosamente de cuando en cuando; 2) como sistema de creencias, sería parte de un "pensamiento salvaje» paralelo al más evolucionado realismo, y 3) lo fantástico es un componente - y explicación- de lo real en el «interior mina».

En general, se podría asumir que, con el correr del tiempo, las «tradiciones» de origen indígena han logrado permear más y más la vida de «interior mina», y por ahí la narrativa. Convergentemente, el discurso literario se ve empujado a integrar más y más lo fantástico hasta hacerlo un componente de lo real. (Esta posibilidad, dicho sea de paso, se puede marcar con Cerco de penumbras [1958], de Oscar Cerruto, donde la literatura boliviana va más allá del realismo para mejor agarrar, precisamente, las más esquivas y múltiples dimensiones de esta realidad.) En esta vena, podemos destacar brevemente tres dimensiones frecuentemente inscritas: la presencia del «Tío», la comprensión de la muerte y una reformulación del hacer en «exterior mina».

El «Tío» es un símbolo de la vida en «interior mina». Su figura de arcilla - la cabeza de diablo, el enorme falo- preside diversos rituales mineros que buscan su protección y ayuda, al mismo tiempo que exorcizan sus oscuros poderes. Es el soberano de los socavones. Como es previsible, algo del diablo de la tradición cristiana se connota en este señor de los

${ }^{9}$ Por ejemplo, la novela Tierras de violencia (1959) está sembrada de relatos que recogen, entre otros, las «leyendas» propias a la vida minera. En «El 'Tío' no existe en los socavones sino en la imaginación del minero», de Adolfo E. de la Quintana (en Poppe 1983, pp. 186-191), como la indirecta del título permite asumir, la figura del «Tío» se introduce para explicar un esquivo hecho «real». Y así en múltiples textos.

${ }^{10}$ Cf. El paraje del Tío y otros relatos mineros (1979). Hasta la fecha, este volumen recoge, prácticamente, toda la obra de Poppe referida, sobre todo, al «interior mina». 
«infiernos» mineros. En algunos textos, el «Tío» asume diversas metamorfosis que pueblan esos oscuros laberintos. Por ello, para no fallarle, cuando los trabajadores se cruzan con alguien allá abajo, siempre saludan respetuosamente: podría ser el «Tío». Entre muchas, esta imagen del «Tío» de Eduardo Galeano:

Los mineros, sentados en rueda, miraban sin pestañear al Tío, su trono alumbrado por el lucerío de las velas, sus sombras espantosas en las paredes de la gruta. En las vasijas, a los pies del Tío, el aguardiente iba bajando de nivel y desapareciendo, las vísceras de las llamas sufrían dentelladas invisibles y las hojas de coca se convertían en pulpa babeada. El cigarrillo se hacía ceniza en la boca del Diablo de barro (en Poppe 1983, p. 175).

Este omnipresente y múltiple personaje del «interior mina» pertenece, seguramente, al «pensamiento mágico», tal como una vez lo caracterizara Borges, como un pensamiento pandeterminista capaz de explicarlo todo desde una cualquier causa. A la vez ladino y protector, el «Tío» motiva el azar en este su mundo: el hallazgo de una rica veta o el accidente son actos de su voluntad, premios o castigos. En su figura, pues, se sugiere la vigencia de un «orden» que regiría en la mina. Un orden quizá no «racional», pero sí coherente.

Referida a las tradiciones indígenas, la muerte es circunstancial y, en rigor, no marca ningún fin ni una especial trascendencia. Aquí los muertos, a su manera, siguen viviendo. Como en el texto de Jaime Sáenz citado en epígrafe (cf. supra), los muertos colaboran con el «Tío» en la protección de los mineros. Las ánimas de los compañeros muertos frecuentan los parajes que los victimaron. Refiriéndose a las creencias indígenas, en su ensayo Compañero de la muerte (en Poppe 1983, pp. 338-341), Gregorio Iriante señala estas características:

Los muertos nunca abandonan a los vivos, siendo como su sombra protectora y hasta vengadores de las injusticias que se cometan contra los suyos.

Consecuente con estas ideas, el minero de origen campesino, mientras trabaja en las entrañas de la tierra, cree estar en continuo contacto con las almas de sus compañeros muertos.

En la mina de Siglo XX, una de las principales secciones se llama «Animas». Un grupo de mineros murió en ese lugar por los efectos de una explosión de dinamita. Según los mineros, sus almas vagan todavía por los socavones (p. 341). 
En la narrativa de «interior mina», esta visión es fuertemente explicativa: abre, sea de manera mítica, el horizonte ya cerrado del ritual propio a la mina tal como lo diseña la de «exterior mina». Y, probablemente, más allá de una posible necesidad o compensación psicológica, como se podría interpretar, esta visión de la muerte construye también una «memoria histórica» -en el sentido de Silvia Rivera Cusicanqui ${ }^{11}$ — capaz de valorar y acumular los valores y contenidos sociales implicados en estos muertos que todavía viven. Cosas así explican la terca lucha de los mineros por un destino mejor pese a las circunstancias que los rodean ${ }^{12}$. En este mundo, lo mítico no está lejos de lo histórico y lo político.

Con este tipo de componentes «ideológicos», la vida en «interior mina» sería la que, en rigor, organizaría — también- la de «exterior mina». Le otorga un sentido. La Khola (1975), de René Poppe, es, a mi entender, el texto que mejor ha explorado y expuesto esta dimensión. Desde ya están el «orden» implícito en la figura del «Tío» y la continuidad afín a la comprensión de la muerte antes señalados. Pero, además, Poppe explicita en términos de «interior mina» los valores organizativos y combativos que

"11 Este concepto de «memoria histórica» o «memoria larga» ha sido propuesto por Silvia Rivera Cusicanqui para explicar los mecanismos de la «memoria colectivas indígena que, así, tiene su propia visión de la historia. Cf. Oprimidos pero no vencidos (1984).

12 Dos textos excepcionales - a mi entender- que tocan la intensidad de esta terquedad histórica son los siguientes. De Sergio Almaraz Paz, «Los cementerios mineros», cuyo final inscribe: «Este que es un país desgarrado al que le predican e imponen una suerte de resignación abyecta ante la debilidad, tiene hombres fuertes que sin ostentación dan de sí mismos todo aquello que permite la permanencia de la vida; ellos mismos son ese terco, milagroso afirmarse constante de la existencia. En una amarga y silenciosa epopeya dejando rastros sangrientos, se entreteje la historia de un pueblo que se obstina en llevar mucho tiempo su pesada cruz en busca de una esperanza que se llama patria» (en Requiem para una República, 1969, pp. 55-65, y también en Poppe 1983, pp. 327-334). En Aluvión de fuego (1935), de Oscar Cerruto, se lee: «Ventarrones de cólera soplan en las almas desmanteladas de los hombres, sacuden sus anchos galpones de abandono y vacío. Cae la mitad de la sonrisa que les colgara, indiferente, en la punta de los labios, y hasta los reflejos de la tranquilidad de los otros les llega con tenebrosa luz. Los hombres pueden mirar a su alrededor y ver que están solos; la arena los rodea y los aísla hasta de su propio corazón; penetra en su mismo corazón y lo inunda. iSoledad, enorme, como si la estrella de sus destinos fuese, de repente, la única brillando opaca en un cielo sin ojos, de arena!

iSoledad de la masa!

$Y$, sin embargo, en ese instante el hombre sería capaz de rechazar enfáticamente otro poder que no sea su propia desgracia. Y su único empeño estará quizá en escupir algo grande y fuerte que él mismo no sabe precisar.

$\mathrm{Si}$ Dios saliese entonces de las Escrituras, la masa lo miraría cara a cara» (1984, pp. 248-249). 
caracterizan a los mineros bolivianos. La vida en «interior mina» sería una especie de política clandestina y sus valores —de experiencia, críticason los que se manifiestan en la superficie. Las analogías con un inconsciente interior que motiva el exterior - more psycoanalitico- podrían traerse como modelo. La tradicional «democracia obrera» es un efecto del trato solidario y compartido que se ejercita en los socavones. Organizativamente, la división del trabajo al interior sustenta la organización sindical y, en caso de una invasión estatal del territorio minero, son las unidades de trabajo las que se transforman en unidades de resistencia. En su desenlace, La Khola también inscribe la tradicional ocupación militar del territorio minero; pero, en sus códigos de «interior mina», la masacre se transforma en victoria gracias a los muertos que, en este ámbito, nunca mueren. Evidentemente, no se trata de una descripción realista, sino de una constitución de sentidos. "Me podrán matar, pero no morir», dice un personaje análogo en El minero, de Benito Pérez (en Poppe 1983, pp. 322-323).

Dada la pertinencia - objetiva y narrativa- de la vida en «interior mina», surge una hipótesis relativa al papel del discurso fantástico: nuestros hábitos lectores reconocen, ciertamente, ese discurso, pero con fronteras y distinciones que, a través del quechua y del aymara, tienen otro tipo de distribución - referencial y explicativa - en el espesor indígena que, en última instancia, caracterizaría la vida minera boliviana. En esta vena, lo indígena, no como abstracción, sino como proceso histórico, quizá es una clave para entender los reales alcances del «conocimiento social» acumulado en la vida minera y que, por ejemplo, pone en evidencia esta narrativa, cuya enunciación siempre tiende a acercarse al minero, que, en el fondo, sería campesino, es decir, indígena.

En este leve recorrido por los discursos que jugarían en la narrativa minera boliviana es difícil sugerir una cualquier preeminencia. El entrecruce de varios discursos (realista, ideológico, histórico, político, fantástico; con dimensiones de referencia y explicación) es fácil de leer aunque se trate de un palimpsesto. Aquí como en otras zonas de la literatura boliviana, el discurso literario asume varias funciones, $y$ su posible autonomía - estética o poética- es problemática. Es que sus flechas de sentido - utilizando la imagen de Wittgenstein - tienden a imbricarse con lo factual. Puesto que el efecto de estas inscripciones en lo social dependen de las condiciones históricas de recepción, se diría que, como nos sugiere la narrativa de «interior mina», esta narrativa es, sobre todo, una búsqueda de sentido quizá análoga a la de la «memoria histórica» propia a las culturas indígenas del altiplano boliviano. Con todo, en nuestro diseño hemos supuesto una cierta función poética: en grueso, a la Jakobson, la proyección vertical $\longleftrightarrow$ horizontal que relacionaría las narrativas de «exterior» e «in- 
terior mina» es también una posibilidad articulatoria de los diversos discursos que aquí operan. La narrativa minera buscaría articular, en intensidad, un amplio espectro que se difunde tanto en extensión como en profundidad. Sus límites son los de la literatura boliviana.

Cochabamba, junio de 1985. 